\title{
Pengaruh Ketersediaan Koleksi Buku Fiksi Terhadap Minat Kunjung Siswa di Perpustakaan SMK Muhammadiyah Gamping Yogyakarta
}

\author{
Bayu Widya Hastoro* \\ Sri Rumani** \\ e-mail: bayu.bacil@gmail.com \\ e-mail: srirumani@ugm.ac.id
}

\begin{abstract}
The purpose of the study is to identify (1) availability of fiction book collection at the library of SMK Muhammadiyah Gamping (2) animo of visits to the library of SMK Muhammadiyah Gamping (3) effects of availability of fiction book collection to animo of visits to the library of SMK Muhammadiyah Gamping (4) the degree of effects of the availability of fiction book collection to animo of visits to the library of SMK Muhammadiyah Gamping. Data were obtained through questionnaire, observation, interview, and documentation. The independent variable is availability of fiction book collection and the dependent variable is animo of visits. Analysis used product moment correlation and simple linear regression. Sampling used accidental technique involving 71 respondents. Data were processed using SPSS 22 for Windows. The result of the study showed there was effect of availability of fiction book collection to animo of visits (tcalculation was 0.644 and ttable 0.227). Thus the hypothesis that there was positive and significat effect of the availability of fiction book collection to animo of visits to the library of SMK Muhammadiyah Gamping was accepted. The degree of effect was obtained through squaring t table with the score 0.415 which indicated that animo of visits was affected by availability of fiction book collection as much as $41.5 \%$ and the rest (58.5\%) was affected by other factors.
\end{abstract}

Keywords: collection availability, fiction books, animo oflibrary visits

*) Mahasiswa UIN Sunan Kalijaga Yogyakarta

**) Pustakawan Fisipol UGM

A. PENDAHULUAN

1. Latar Belakang

Pendidikan merupakan bagian terpenting bagi perkembangan manusia. Salah satu sarana penting sebagai pondasi pendidikan adalah perpustakaan. Undang-Undang Nomor 43 Tahun 2007 tentang perpustakaan menyebutkan bahwa setiap sekolah/madrasah menyelenggarakan perpustakaan yang memenuhi Standar Nasional Perpustakaan dengan memperhatikan Standar Nasional Pendidikan. Disebutkan pula bahwa selain wajib memiliki koleksi buku teks pelajaran yang ditetapkan sebagai buku teks wajib pada satuan pendidikan yang bersangkutan, perpustakaan sekolah juga diwajibkan mengembangkan koleksi lain yang mampu mendukung pelaksanaan kurikulum pendidikan.
Menanggapi pernyataan tentang koleksi perpustakaan, setiap perpustakaan memiliki koleksi sebagai sumber informasi. Ketersediaan koleksi harus diperhatikan sesuai dengan prinsip perkembangan koleksi perpustakaan. Salah satu jenis perkembangan koleksi perpustakaan adalah koleksi dalam bentuk fiksi. Mindrep (2005:1) menyebutkan bahwa koleksi fiksi mempunyai sisi hiburan yang ringan dan mengandung banyak unsur pendidikan. Perbandingan jumlah koleksi fiksi di perpustakaan sebaiknya sebanyak $30-40 \%$ dari jumlah koleksi keseluruhan. Koleksi perpustakaan yang baik harus mencerminkan kebutuhan pemustaka. Hal ini dikarenakan perpustakaan harus mampu menarik minat kunjung pemustaka dengan tersedianya koleksi.

Keberagaman koleksi dapat menjadi motivasi siswa dalam berkunjung. Tersedianya 
koleksi di perpustakaan, menjadikan siswa lebih mudah memperoleh informasi yang sesuai dengan kebutuhannya. Hal tersebut diperkuat dengan pernyataan Gren (2012:342) bahwa lembaga sekolah sebaiknya menyediakan koleksi yang beragam agar peserta didik mendapatkan pengetahuan yang lebih luas. Keberagaman koleksi tersebut juga menyediakan buku pendukung di perpustakaan, termasuk fiksi. Dari penjelasan tersebut, dapat dipahami bahwa buku fiksi dapat menjadi salah satu cara membangkitkan minat siswa untuk membaca dan berkunjung ke perpustakaan.

Selain ketersediaan koleksi buku fiksi, Surachman(2010:35) menyebutkan bahwa terdapat faktor lain yang mempengaruhi minat kunjung di perpustakaan sekolah yaitu layanan. Layanan yang baik dan ramah membuat siswa betah berkunjung ke perpustakaan. Kemudian, keadaan lingkungan berpengaruh terhadap minat kunjung perpustakaan. Menurut IFLA/UNESCO(2006:11) dijelaskan penampilan perpustakaan yang menarik dapat memberikan rasa nyaman dan dapat merangsang siswa menggunakan waktunya di perpustakaan. Selanjutnya, Gren (2012:343) menjelaskan bahwa salah satu faktor yang mempengaruhi minat kunjung adalah jam layanan perpustakaan. Perpustakaan perlu mengefektifkan jam kunjung perpustakaan agar pemustaka mampu memanfaatkan waktu kunjung perpustakaan dengan baik.

Meninjau dari beberapa faktor yang mempengaruhi minat kunjung, dalam penelitian ini peneliti hanya mengkaji faktor ketersediaan koleksi fiksi saja. Hal ini berdasarkan pada teori Bafadal (2008:8) yang menyebutkan bahwa salah satu fungsi perpustakaan adalah rekreasi. Oleh karena itu perpustakaan harus menyediakan koleksi yang menghibur seperti koleksi fiksi. Siswa belajar terus menerus membuat lebih cepat bosan dan jenuh, maka untuk mendapatkan hiburan dan pembelajaran, siswa dapat membaca buku fiksi seperti novel, roman, syair dan lainnya.

Salah satu jenis perpustakaan sekolah yaitu perpustakaan Sekolah Menengah Kejuruan (SMK). Pada umumnya perpustakaan di sekolah swasta tidak terawat dan terorganisir dengan baik. Selain itu, perpustakaan swasta koleksinya kurang dari standar perpustakaan yaitu 1000 judul buku. Akan tetapi, Perpustakaan SMK Muhammadiyah Gamping memiliki koleksi lebih dari 1000 judul buku.Oleh karena itu, peneliti tertarik untuk memilih siswa SMK Muhammadiyah Gamping sebagai sampel dalam penelitian ini.

Perpustakaan SMK Muhammadiyah Gamping memiliki koleksi fiksi dan nonfiksi. Jumlah koleksi nonfiksi sebesar 1.056 judul buku dan koleksi fiksi sebesar 318 judul buku dengan total koleksi 1.374 judul buku. Sehingga, prosentase buku fiksi di Perpustakaan SMK Muhammadiyah Gamping sebanyak 23\% dari total judul buku. Sedangkan kunjungan di Perpustakaan SMK Muhammadiyah Gamping Pada tahun 2013 sebesar 808 kunjungan dan tahun 2014 sebesar 674 kunjungan. Oleh karena itu, kunjungan dari tahun 2013-2014 mengalami penurunan sebesar $17 \%$.

Bedasarkan wawancara yang dilakukan peneliti pada tanggal 25 Maret 2015 jam 09.00 dengan Ibu Lita pustakawan di SMK Muhamadiyah Gamping, penyebab utama menurunnya minat kunjung yaitu perkembangan teknologi sehingga siswa lebih mudah mengakses informasi. Sedangkan kondisi Perpustakaan SMK Muhammadiyah Gamping saat inimasih dalam proses berkembang. Kondisi ketersediaan koleksi fiksi tidak sebanding dengan minat kunjung siswa,hal ini menarik peneliti untuk kajian dengan judul "Pengaruh Ketersediaan Koleksi Fiksi Terhadap Minat Kunjung Siswa di Perpustakaan Muhammadiyah Gamping Yogyakarta".

\section{Rumusan masalah}

Berdasarkan latar belakang, peneliti merumuskan masalah sebagai beikut.

1. Bagaimana ketersediaan koleksi fiksi di Perpustakaan Sekolah Menengah Kejuruan (SMK) Muhammadiyah Gamping?

2. Bagaimana minat kunjung di Perpustakaan SMK Muhammadiyah Gamping?

3. Apakah ada pengaruh antara ketersediaan koleksi buku fiksi terhadap minat kunjung siswa di Perpustakan SMK Muhammadiyah Gamping?

4. Seberapa besar pengaruh keter-sediaan koleksi buku fiksi terhadap minat kunjung siswa di Perpustakan SMK Muhammadiyah Gamping? 


\section{B. TINJAUAN PUSTAKA}

\section{Ketersediaan Koleksi}

Menurut Lasa (2009:158) ketersediaan judul adalah jumlah judul koleksi perpustakaan yang benar-benar tersedia/tertulis pada cantuman perpustakaan apabila sewaktu-waktu diakses oleh pemustaka. Berdasarkan uraian tersebut, dijelaskan bahwa ketersediaan koleksi perpustakaan adalah semua bahan pustaka yang dimiliki oleh perpustakaan dan disajikan kepada pemustaka untuk memenuhi kebutuhan informasi. Hal tersebut dapat diartikan bahwa setiap bahan pustaka yang dibutuhkan oleh pemustaka, disediakan di perpustakaan meskipun tidak semuanya berada di perpustakaan. Hal tersebut dikarenakan tidak ada perpustakaan yang mampu menyimpan seluruh bahan informasi.

Menurut Sutarno (2006:109) mengembangkan minat harus dilakukan secara terus menerus dan diperlukan ketersediaan bahan bacaan yang memadai mencakup:

\section{a. Jenis koleksi perpustakaan}

Menurut Sutarno (2006:69) koleksi perpustakaan mencakup bahan pustaka yang terpilih, informasi yang ada cocok dengan keperluan pemustakanya. Koleksi yang sudah berada di perpustakaan adalah bahan pustaka yang sudah mengalami pengolahan dan siap untuk di-manfaatkan.

Ditinjau dari bentuk fisiknya koleksi perpustakaan terbagi menjadi dua yaitu koleksi buku dan koleksi nonbuku. Koleksi yang bukan buku dibagi lagi menjadi dua kelompok yaitu bahan tertulis dan bahan berupa alat peraga. Sedangkan ditinjau dari isinya koleksi dibagi menjadi dua jenis yaitu koleksi fiksi dan nonfiksi.

Darmono (2007:65-66) menjelaskan beberapa jenis koleksi perpustakaan sebagai berikut:

a) Buku adalah koleksi cetak yang sering dihimpun di perpustakaan. Buku mempunyai dua jenis buku seperti buku teks dan buku penunjang.

b) Koleksi referensi berbentuk buku tetapi yang membedakan yakni isi dan penyajiannya. Isi buku referensi tidak mendalam dan hanya memuat informasi tertentu seperti arti kata.

c) Sumber geografi merupakan koleksi yang berisi informasi tentang alam seperti kondisi cuaca atau iklim. Bentuk sumber geografi pada umumnya adalah atlas, globe, peta dan lainnya.

d) Jenis serial (terbitan berkala) adalah publikasi yang direncanakan terbit secara terus menerus tanpa terbatas waktu. Publikasi ini diterbitkan oleh lembaga atau yayasan yang membentuk susunan redaksi sebagai penanggung jawab. Tulisan yang dimuat di terbitan berkala berupa ide, gagasan, hasil penelitian, dan pemikiran asli penulis.

b. Jumlah koleksi perpustakaan

Standar koleksi perpustakaan bergantung pada situasi dan kondisi perpustakaan. Hal yang harus dijadikan perhatian yaitu jumlah judul dan jumlah eksemplar buku. Perpustakaan harus memilih lebih mementingkan jumlah eksemplar buku atau jumlah judul buku tertentu. Buku yang menjadi kegemaran pemustaka sebaiknya jumlah eksemplarnya lebih banyak daripada jumlah buku yang tidak pernah dipinjam.

Menurut pedoman perpus-takaan sekolah menurut IFLA/UNESCO (2006:13) perpustakaan sekolah menyediakan koleksi yang sesuai dengan kebutuhan sebanyak sepuluh buku per siswa. Perbandingan jumlah koleksi paling sedikit $60 \%$ koleksi perpustakaan terdiri dari buku nonfiksi yang berkaitan dengan kurikulum dan 40\% koleksi fiksi.Sekolah terkecil memiliki koleksi yang relevan dan mutakhir agar stok buku berimbang untuk semua umur, kemampuan dan latar belakang.

Menurut Standar Nasional Perpustakaan, koleksi perpustakaan SMA harus memiliki satu teks eksemplar per mata pelajaran per siswa dan memiliki satu buku panduan pendidik per mata pelajaran per guru bidang studi. Perbandingan jumlah koleksi buku nonfiksi sebanyak $70 \%$ dan koleksi fiksi sebanyak $30 \%$.

c. Kualitas koleksi perpustakaan

Untuk memberikan pelayanan yang baik kepada pemustaka, perpustakaan 
perlu memperhatikan berbagai aspek. Salah satunya kualitas koleksi perpustakaan. Hal tersebut dapat dilihat dari bentuk fisik dan isi dari bahan pustaka. Kualitas fisikbahan yang dipilih harus tercetak dalam huruf yang berspasi rata dan dalam tipe huruf yang cukup besar sehingga dapat dibaca dengan mudah. Penjilidannya harus kuat, menarik dan buku harus dapat dibuka dengan mudah. Margin halaman harus cukup lebar untuk memungkinkan penjilidan ulang serta jika pembaca mau memfotokopi tidak merusak penjilidan. Ilustrasi harus sesuai dengan isi buku dan ditempatkan di tempat yang sesuai. Penerbit karya yang dipilih harus merupakan produk penerbit dengan standar kualitas yang tinggi dan reputasi yang baik khususnya dalam penyajian materi (Qalyubi dkk, 2007:102-103)

Dilihat dari kualitas isi koleksi, perpustakaan tidak boleh menyediakan koleksi yang mengandung unsur sara, pornografi, profokatif dan lainnya. Koleksi perpustakaan harus memenuhi kriteria yaitu: relevan dengan kebutuhan pemakai, mutakhir, sesuai dengan spesialis bidang, berkualitas dan sesuai dengan visi dan misi lembaga induknya.Relevan yang dimaksud yaknikesesuaian bahan informasi dengan keperluan pemakai dan dapat menambah wawasan bagi pembacanya. Bahan koleksi yang disediakan memenuhi syarat kualitas yang ditentukan, seperti berkaitan dengan subyek, reputasi pengarang dan reputasi penerbit. Perlu diperhatikan juga tentang fisik bahan informasi seperti kertas, pita, lay out, label, warna, sampul dan lainnya. Hal tersebut disebabkan karena banyak beredar bahan koleksi di pasaran yang harganya jauh lebih murah dari harga aslinya. Dengan kualitas yang baik pengguna akan lebih nyaman untuk memanfaatkan koleksi dan eksistensi perpustakaan dapat terjaga (Lasa Hs, 2005:122-123).

\section{Minat Kunjung}

Menurut Bafadal (2008:191) minat adalah sifat atau sikap yang memiliki kecenderungan hati yang tinggi terhadap sesuatu.Sedangkan menurut Sutarno (2003:19) minat adalah kecenderungan hati yang tinggi, gairah atau keinginan seseorang terhadap sesuatu. Dari penjelasan di atas dapat disimpulkan minat adalah keadaan dimana seseorang mempunyai keinginan yang tinggi terhadap sesuatu.

Kamus Besar Bahasa Indonesia (2008:476) menjelaskan kunjung adalah kegiatan untuk mendatangi. Peneliti mengambil kesimpulan, minat kunjung adalah keadaan dimana seseorang mempunyai keinginan untuk berkunjung. Menurut Lasa (2009:14) minat kunjung juga merupakan indikator minat baca dan minat ilmu yang tinggi diukur dari tinggi rendahnya kunjungan. Seseorang mengunjungi perpustakaan tentunya untuk meminjam koleksi di perpustakaan, namun tidak sedikit pemustaka sengaja datang ke perpustakaan untuk mencari informasi tertentu yang dibutuhkan.

Menurut Sutarno (2003:29) ada beberapa hal yang mempengaruhi minat kunjung, yaitu :

1) Rasa ingin tahu yang tinggi

Seseorang yang berminat terhadap sesuatu karena tertarik dan ingin tahu.Keinginan pada dasarnya sudah ada pada setiap orang sejak kecil dan terus berkembang. Seseorang akan tertarik tentang sesuatu apabila sesuatu itu berguna dan menyenangkan sehingga termotivasi untuk mengetahui lebih dalam dengan serius. Oleh karena itu, perpustakaan perlu melakukan inovasi untuk menciptakan perpustakaan yang menarik.

2) Keadaan lingkungan yang memadai

Menurut Sutarno (2006:123) lingkungan yang baik memiliki andil dalam penyelengaraan perpustakaan. Lingkungan tersebut mencakup lokasi yang strategis, mudah dikenal dan dijangkau masyarakat, bebas banjir, bersih, tenang, dan terdapat akses kendaraan.

Pemeliharaaan gedung merupa-kan bagian yang penting dan perlu mendapat perhatian. Gedung yang terpelihara dengan baik dan tampak rapi dan bersih menyebabkan pengunjung betah berada di perpustakaan. Untuk membuat lingkungan tampak indah dan asri juga perlu memperhatikan lingkungan penunjang di sekitar perpustakaan seperti pemeliharaan taman. Manfaat penataan ruang perpustakaan dapat mempermudah siswa, guru dan pengunjung lainnya dalam 
memperoleh bahan pustaka yang diinginkan. Dengan kemudahan tersebut mempengaruhi minat kunjung di perpustakaan. Hal yang perlu diperhatikan dalam penataan ruang yaitu penerangan, pengaturan sirkulasi udara, penataan meja dan kursi belajar dan penataan ruang kerja petugas. Lingkungan yang baik membuat pemustaka nyaman dan senang berada di perpustakaan. Lingkungan yang demikian merupakan salah satu faktor yang berpengaruh positif terhadap peran perpustakaan (Darmono, 2007:199-201).

3) Minat kunjung Perpustakaan sebagai kebutuhan

Koleksi perpustakaan yang diminati oleh seseorang akan memiliki manfaat, nilai yang sesuai dengan apa yang diinginkan pemustaka. Nilai dan manfaat tersebut dapat menambah pengetahuan, memberikan hiburan, kepuasan bahkan menimbulkan rasa bangga pada diri seseorang. Selain itu, akan menghasilkan perubahan pada kemampuan, sikap maupun keterampilan. Manusia yang tekun belajar dan mengunjungi perpustakaan diharapkan dapat menjadi manusia yang menguasai informasi, pengetahuan, wawasan, berperilaku arif dan bijaksana (Sutarno, 2006:108).

Mengembangkan minat dan respon masyarakat untuk berkunjung dan memanfaatkan perpustakaan secara maksimal diperlukan kesadaran diri bukan paksaan. Sehingga dengan berprinsip mengunjungi perpustakaan dapat memaksimalkan fungsi dan merasakan manfaat dari perpustakaan. Jika masyarakat sudah merasa membutuhkan perpustakaan, disanalah peran, fungsi dan tugas perpustakaan diaplikasikan (Suwarno, 2009:23).

Dalam Standar Nasional Perpustakaan (2011:4) dijelaskan bahwa perpustakaan harus menjalankan program wajib berkunjung setiap kelas diwajibkan berkunjung ke perpustakaan minimal satu jam pelajaran per minggu. Dengan demikian bahwa setiap siswa harus mengunjungi perpustakaan minimal sekali setiap harinya. Sehingga idealnya kunjungan perpustakaan dalam seminggu sebanding jumlah siswa yang ada dalam perpustakaan tersebut.

Intensitas kunjungan di perpustakaan dapat diukur melalui daftar hadir pengunjung perpustakaan. Setiap pemustaka yang datang berkunjung ke perpustakaan diwajibkan mengisi daftar hadir pengunjung perpustakaan. Daftar hadir pengunjung perpustakaan tersebut dapat secara manual ataupun elektronik. Hasilnya dapat terlihat dari tabel dan grafik kunjungan yang berada di perpustakaan.

\section{METODE PENELITIAN}

Jenis penelitian yang digunakan dalam penelitian ini yakni penelitian deskriptif kuantitatif. Menurut Arikunto (2010:3) penelitian deskriptif merupakan penelitian yang dimaksudkan untuk menyelidiki keadaan, kondisi dengan pengumpulan fakta, identifikasi, dan meramalkan hubungan dalam dan antar variabel. Sedangkan, menurut Suharso (2009:3) penelitian kuantitatif adalah penelitian yang spesifikasinya sudah sistematis sejak awal dan variabel terukur dengan skala nominal, ordinal, interval, dan rasio.

Subyek dalam penelitian ini yaitu seluruh siswa di SMK Muhammadiyah Gamping dan obyek dalam penelitian ini adalah yaitu ketersediaan koleksi fiksi terhadap minat kunjung siswa. Populasi pada penelitian ini berjumlah 241 diperoleh dari buku anggota perpustakaan pada tahun 2014. Pengambilan sampel menggunakan rumus Taro Yamane dalam (Hamidi, 2010:131). Sampel yang diperoleh menggunakan rumus tersebut sejumlah 71 responden. Sedangkan untuk teknik pengambilan sampelnya, peneliti menggunakan teknik sampling insidental. Menurut Sugiyono (2013:85) sampling insidental adalah pengambilan sampel berdasarkan kebetulan atau siapa saja yang kebetulan bertemu dengan peneliti dan dirasa cocok untuk dijadikan sampel. 


\begin{tabular}{|c|c|c|c|c|}
\hline Variabel & $\begin{array}{c}\text { Sub } \\
\text { Variabel }\end{array}$ & Indikator & Item & Jumlah \\
\hline \multirow{6}{*}{$\begin{array}{l}\text { Ketersedia } \\
\text { an koleksi } \\
\text { fiksi } \\
\text { (Sutarno, } \\
\text { 2006:109). }\end{array}$} & \multirow{3}{*}{$\begin{array}{l}\text { Jenis } \\
\text { Koleksi }\end{array}$} & $\begin{array}{l}\text { Keberagaman } \\
\text { koleksi }\end{array}$ & $1,2,3$ & 3 \\
\hline & & $\begin{array}{l}\text { Sesuai } \\
\text { Kebutuhan }\end{array}$ & 4,5 & 2 \\
\hline & & Banyak koleksi & 6,7 & 2 \\
\hline & $\begin{array}{l}\text { Jumlah } \\
\text { Koleksi }\end{array}$ & $\begin{array}{l}\text { Keseimbangan } \\
\text { koleksi }\end{array}$ & 8,9 & 2 \\
\hline & Kualitas & Kualitas isi & 10,11 & 2 \\
\hline & koleksi & Kualitas fisik & 12,13 & 2 \\
\hline \multirow{9}{*}{$\begin{array}{l}\text { Minat } \\
\text { Kunjung } \\
\text { (Sutarno, } \\
\text { 2003:39). }\end{array}$} & Rasa & Motivasi & 14,15 & 2 \\
\hline & $\begin{array}{l}\text { ingin } \\
\text { tahu }\end{array}$ & $\begin{array}{l}\text { Inovasi } \\
\text { Perpustakaan }\end{array}$ & $\begin{array}{l}16,17 \\
18,19\end{array}$ & 4 \\
\hline & \multirow{3}{*}{$\begin{array}{l}\text { Keadaan } \\
\text { lingkungan }\end{array}$} & Lokasi strategis & 20,21 & 2 \\
\hline & & Tata ruang & 22,23 & 2 \\
\hline & & Kenyamanan & 24,25 & 2 \\
\hline & \multirow{4}{*}{$\begin{array}{l}\text { Prinsip } \\
\text { kebutuhan }\end{array}$} & Sesuai & 26 & 1 \\
\hline & & kehendak & & \\
\hline & & pemustaka & & \\
\hline & & Kesadaran diri & 27,28 & 2 \\
\hline & \multicolumn{2}{|c|}{ JUMLAH } & & 28 \\
\hline
\end{tabular}

Menurut Sugiyono (2013:102) instrumen penelitian adalah suatu alat yang digunakan peneliti untuk mengukur fenomena yang diamati. Berikut adalah tabel instrumen penelitian dalam penelitian ini.

Analisis data dalam penelitian ini menggunakan rumus grand-mean. Alat yang digunakan untuk menghitung nilai rata-rata dari variabel ketersediaan koleksi dan minat kunjung menggunakan rumus mean. Bobot nilai mendekati 4 menunjukan besarnya mean karena mayoritas tanggapan responden sangat setuju. Tetapi, apabila mayoritas tanggapan yang diberikan responden sangat tidak setuju, maka besarnya nilai mean akan mendekati nilai 1 . Analisis data dalam dalam penelitian ini menggunakan rumus sebagai berikut:

1. Mean $=X=\frac{\Sigma x}{N}$

Keterangan:

$X=$ rata-rata hitung

$\sum x=$ jumlah semua nilai kuesioner

$N=$ jumlah responden

2. Grand Mean $(x)=\frac{\text { total rata }- \text { rata hitung }}{\text { jumlah responden }}$

Sedangkan untuk interval hasil perhitungan tersebut peneliti menggunakan skor rata-rata (MX) yang dikemukakan oleh Mustafa (2013:150) dengan menghitung terlebih dahulu interval setiap kategori. Dengan menggunakan interval setiap kategori 0,75, maka nilai interval rata-rata hitung adalah sebagai berikut:

Tabel 2. Interpretasi nilai rata-rata hitung

\begin{tabular}{ll}
\hline Interval Koefisien & Tingkat Hubungan \\
\hline $1,00-1,75$ & Sangat Rendah \\
$1,76-2,50$ & Rendah \\
$2,51-3,25$ & Tinggi \\
$3,26-4,00$ & Sangat Tinggi \\
\hline & Sumber: Data Primer Diolah Mei 2015
\end{tabular}

Uji Hipotesis penelitian ini menggunakanrumus korelasi product moment. Rumus tersebut untuk mengetahui apakah ada pengaruh ketersediaan koleksi fiksi terhadap minat kunjung siswa di Perpustakaan SMK Muhammadiyah Gamping. Berikut adalah rumus korelasi rumus product moment.

$$
r_{x y}=\frac{N \Sigma x y-(\Sigma x)(\Sigma y)}{\sqrt{\left\{N \Sigma x^{2}-(\Sigma x)^{2}\right\}\left\{N \Sigma y^{2}-(\Sigma y)^{2}\right\}}}
$$

Keterangan:

$r_{x y}=$ Koefisien korelasi antara skor butir dengan skor total

$N=$ Jumlah subjek uji coba

$\Sigma x=$ Jumlah skor butir $(\mathrm{x})$

$\Sigma x^{2}=$ Jumlah skor butir kuadrat (x)

$\Sigma y=$ Jumlah skor total (y)

$\Sigma y^{2}=$ Jumlah skor total kuadrat $(\mathrm{Y})$

$\Sigma x y=$ Jumlah per kalian skor total butir dengan skor total

Selanjutnya untuk mengetahui hubungan yang ditemukan tersebut berlaku untuk keseluruhan populasi atau tidak, maka diperlukan uji signifikansi hubungan (Sugiyono,2013:184). Menurut Sugiyono (2013:185) uji signifikansi korelasi product moment secara praktis atau yang tidak perlu dihitung dengan rumus $t$ dapat dilakukan dengan mengkonsultasikan pada tabel $\mathrm{r}$ product moment.

Setelah koefisien korelasi antar variabel ditentukan maka peneliti akan melanjutkan menghitung koefisien determinasi dengan mengkuadratkan koefisien yang ditemukan (Sugiyono,2013:185).

\section{HASIL DAN PEMBAHASAN}

Data tentang ketersediaan koleksi diperoleh melalui angket dengan jumlah 6 
indikator dan jumlah item sebanyak 13 butir. Sebelum kuesioner tersebut disebarkan, peneliti terlebih dahulu melakukan uji validitas dan reliabilitas terhadap 30 orang responden. Berdasarkan hasil uji tersebut semua item kuesioner yang dibuat sudah valid. Berikut ini hasil dari pengolahan data variabel lokasi dan minat kunjung menggunakan rumus mean dan grandmean.

Tabel 3. Jawaban Responden Tentang Variabel Ketersediaan Koleksi Fiksi (X)

\begin{tabular}{|c|c|c|c|c|c|c|c|}
\hline \multirow[b]{2}{*}{ No. } & \multirow[b]{2}{*}{ Pernyataan } & \multicolumn{4}{|c|}{ Skor } & \multirow[b]{2}{*}{ Total } & \multirow[b]{2}{*}{ Mean } \\
\hline & & 1 & 2 & 3 & 4 & & \\
\hline 1 & $\begin{array}{l}\text { Perpustakaan memiliki koleksi } \\
\text { fiksi seperti novel, komik, } \\
\text { roman, drama, puisi dan syair }\end{array}$ & 1 & 5 & 34 & 31 & 71 & 3,34 \\
\hline 2 & $\begin{array}{l}\text { Koleksi perpustakaan yang } \\
\text { sering dipinjam yakni koleksi } \\
\text { fiksi }\end{array}$ & 1 & 16 & 49 & 5 & 71 & 2,81 \\
\hline 3 & $\begin{array}{l}\text { Koleksi fiksi paling banyak di } \\
\text { perpustakaan yakni novel. }\end{array}$ & 6 & 22 & & 10 & 71 & 2,66 \\
\hline 4 & $\begin{array}{l}\text { Koleksi di perpustakaan sesuai } \\
\text { dengan kebutuhan }\end{array}$ & 1 & 4 & 37 & 29 & 71 & 3,32 \\
\hline 5 & $\begin{array}{l}\text { Informasi yang diperlukan } \\
\text { selalu ada di perpustakaan }\end{array}$ & 1 & 7 & 31 & 32 & 71 & 3.32 \\
\hline 6 & $\begin{array}{l}\text { Judul koleksi fiksi di } \\
\text { perpustakaan beragam } \\
\text { Perpustakaan perlu }\end{array}$ & 0 & 5 & 38 & 28 & 71 & 3,32 \\
\hline 7 & $\begin{array}{l}\text { menambahkan jumlah buku } \\
\text { dengan judul yang sama } \\
\text { Jumlah koleksi fiksi dan non }\end{array}$ & 1 & 18 & 30 & 22 & 71 & 3,02 \\
\hline 8 & $\begin{array}{l}\text { fiksi di perpustakaan sudah } \\
\text { memenuhi kebutuhan }\end{array}$ & 0 & 22 & 38 & 11 & 71 & 2,84 \\
\hline 9 & $\begin{array}{l}\text { Setiap judul buku di } \\
\text { perpustakaan memiliki jumlah } \\
\text { buku lebih dari satu }\end{array}$ & 0 & 0 & 35 & 36 & 71 & 3,50 \\
\hline 10 & $\begin{array}{l}\text { Kualitas isi buku fiksi di } \\
\text { perpustakaan tidak mengandung } \\
\text { unsur sara, pornografi dan } \\
\text { profokatif }\end{array}$ & 4 & 6 & 23 & 38 & 71 & 3,39 \\
\hline 11 & $\begin{array}{l}\text { Isi buku di perpustakaan sesuai } \\
\text { dengan yang dibutuhkan }\end{array}$ & 0 & 4 & 30 & 37 & 71 & 3,46 \\
\hline 12 & $\begin{array}{l}\text { Kondisi sampul buku masih } \\
\text { bagus }\end{array}$ & 2 & 10 & 28 & 31 & 71 & 3,24 \\
\hline 13 & $\begin{array}{l}\text { Tidak terdapat kotoran di dalam } \\
\text { buku }\end{array}$ & 1 & 13 & 32 & 25 & 71 & 3,14 \\
\hline \multicolumn{8}{|c|}{ Grand Mean } \\
\hline
\end{tabular}

Berdasarkan tabel 3 di atas menunjukkan bahwa secara keseluruhan variabel ketersediaan koleksi tergolong tinggi dengan nilai rata-rata 3,15 dengan 6 indikator. Nilai tertinggi terlihat oleh indikator kualitas isi dengan nilai 3,42 dan yang terendah terlihat pada indikator keberagaman koleksi dengan nilai 2,64.

Data tentang minat kunjung diperoleh melalui angket dengan jumlah 7 indikator dan jumlah item sebanyak 15 butir. Data pada masing-masing item untuk minat kunjung sebagai berikut.

\begin{tabular}{|c|c|c|c|c|c|c|c|c|}
\hline \multirow{3}{*}{ No } & \multicolumn{8}{|c|}{$\begin{array}{c}\text { Tabel 4. Jawaban Responden Tentang } \\
\text { Variabel Minat Kunjung (Y) }\end{array}$} \\
\hline & Pernyataan & & & kor & & Tot & Mean & Grand \\
\hline & Pernyataan & 1 & 2 & 3 & 4 & al & Mean & Mean \\
\hline 1 & $\begin{array}{l}\text { Perpustakaan mampu } \\
\text { memberikan informasi }\end{array}$ & 0 & 1 & 33 & 37 & 71 & 3,50 & \multirow{2}{*}{3,37} \\
\hline 2 & $\begin{array}{l}\text { Koleksi fiksi di } \\
\text { perpustakaan menarik }\end{array}$ & 0 & 9 & 36 & 26 & 71 & 3,24 & \\
\hline 3 & $\begin{array}{l}\text { Terdapat berbagai program } \\
\text { yang menarik di } \\
\text { perpustakaan }\end{array}$ & 1 & 7 & 41 & 22 & 71 & 3,18 & \multirow{4}{*}{2,95} \\
\hline 4 & $\begin{array}{l}\text { Perpustakaan mengadakan } \\
\text { berbagai macam lomba }\end{array}$ & 3 & 21 & 35 & 12 & 71 & 2,78 & \\
\hline 5 & $\begin{array}{l}\text { Siswa berpartisipasi dalam } \\
\text { kegiatan lomba di } \\
\text { perpustakaan }\end{array}$ & 5 & 20 & 32 & 14 & 71 & 2,27 & \\
\hline 6 & $\begin{array}{l}\text { Setting tata ruang } \\
\text { perpustakaan berubah secara } \\
\text { berkala }\end{array}$ & 1 & 19 & 25 & 26 & 71 & 3,07 & \\
\hline 7 & $\begin{array}{l}\text { Lokasi perpustakaan mudah } \\
\text { didatangi pengunjung }\end{array}$ & 0 & 1 & 30 & 40 & 71 & 3,55 & \multirow[b]{2}{*}{3,53} \\
\hline 8 & $\begin{array}{l}\text { Akses menuju ke } \\
\text { perpustakaan mudah } \\
\text { dijangkau }\end{array}$ & 0 & 2 & 30 & 39 & 71 & 3,52 & \\
\hline 9 & $\begin{array}{l}\text { Ruangan di perpustakaan } \\
\text { mendukung untuk belajar }\end{array}$ & 1 & 11 & 25 & 34 & 71 & 3,29 & \multirow{2}{*}{3,37} \\
\hline 10 & $\begin{array}{l}\text { Koleksi perpustakaan ditata } \\
\text { dengan rapi }\end{array}$ & 0 & 7 & 25 & 39 & 71 & 3,45 & \\
\hline 11 & $\begin{array}{l}\text { Perpustakaan menyediakan } \\
\text { tempat untuk membaca }\end{array}$ & 0 & 7 & 27 & 37 & 71 & 342 & \multirow{2}{*}{3,25} \\
\hline 12 & $\begin{array}{l}\text { Suasana perpustakaan tidak } \\
\text { terlalu bising untuk belajar }\end{array}$ & 4 & 12 & 29 & 26 & 71 & 3,08 & \\
\hline 13 & $\begin{array}{l}\text { Berkunjung ke perpustakaan } \\
\text { untuk belajar }\end{array}$ & 0 & 6 & 30 & 35 & 71 & 3,40 & 3,40 \\
\hline 14 & $\begin{array}{l}\text { Koleksi di perpustakaan } \\
\text { dapat menambah wawasan } \\
\text { dan pengetahuan }\end{array}$ & 0 & 2 & 27 & 42 & 71 & 3,56 & \multirow{2}{*}{3,47} \\
\hline 15 & $\begin{array}{l}\text { Perpustakaan mampu } \\
\text { menjadi tempat untuk } \\
\text { menghilangkan rasa jenuh }\end{array}$ & 0 & 5 & 33 & 33 & 71 & 3,39 & \\
\hline \multicolumn{8}{|c|}{ Grand Mean } & 3,33 \\
\hline
\end{tabular}

Berdasarkan tabel 4 menunjukkan bahwa secara keseluruhan variabel minat kunjung tergolong sangat tinggi dengan nilai rata-rata 3,33 dengan 7 indikator. Nilai tertinggi indikator lokasi strategis dengan skor 3,53 dan yang terendah pada indikator inovasi dengan skor 2,95.

Selanjutnya, dilakukan uji hipotesis menggunakan rumus product moment. Dalam menganalisis korelasi digunakan program SPSS versi 22 for windows. Berikut hasil korelasi variabel ketersediaan koleksi dan variabel minat kunjung.

Tabel 5. Hasil Uji Hipotesis Uji Korelasi Correlations

\begin{tabular}{llcc}
\hline & & $\begin{array}{c}\text { Ketersediaan } \\
\text { Koleksi }\end{array}$ & $\begin{array}{c}\text { Minat } \\
\text { Kunjung }\end{array}$ \\
\hline Ketersediaan & Pearson Correlation & 1 & $.644^{* *}$ \\
Koleksi & Sig. (2-tailed) & & .000 \\
& $\mathrm{~N}$ & 71 & 71 \\
\hline Minat & Pearson Correlation & $.644^{* *}$ & 1 \\
Kunjung & Sig. (2-tailed) & .000 & \\
& N & 71 & 71 \\
\hline **. Correlation is significant at the 0.01 level (2-tailed). \\
\hline \multicolumn{3}{c}{ Sumber: Data Primer Diolah Mei 2015 } \\
\multicolumn{3}{c}{}
\end{tabular}

Berdasarkan hasil analisis data di atas bahwa nilai koefisien korelasi yang diperoleh sebesar 0,644. Nilai koefisien $\mathrm{r}$ tabel dengan $\mathrm{N}$ 
sebesar 71 adalah 0,227 (Sugiyono, 2013:333). Dengan demikian nilai koefesien lebih besar daripada $r$ tabel $(0.644>0,227)$, sehingga nilai tersebut bernilai positif dan terdapat pengaruh antara variabel $\mathrm{X}$ dan variabel $\mathrm{Y}$.

Menurut kategori koefisien korelasi, nilai koefisien korelasi sebesar 0,644 berada pada kategori kuat. Sehingga ketersediaan koleksi fiksi berpengaruh kuat terhadap minat kunjung siswa di SMK Muhammadiyah Gamping.

Selanjutnya dilakukan uji signifikansi untuk mengetahui hubungan variabel ketersediaan koleksi dan variabel minat kunjung berlaku untuk keseluruhan populasi. Dengan ketentuan apabila $r$ hitung lebih kecil dari $r$ tabel, maka Ho diterima dan Ha ditolak. Sedangkan apabila $r$ hitung lebih besar dari $r$ tabel maka Ha diterima dan Ho ditolak. Hasil dari $\mathrm{r}$ hitung dari korelasi variabel $\mathrm{X}$ dan variabel Y adalah 0,644 dan taraf signifikan 5\% bernilai 0,227. Dengan demikian koefisien korelasi tersebut signifikan karena r hitung lebih besar dari $r$ tabel $(0,644>0,227)$. Maka Ha diterima dan Ho ditolak, artinya terdapat pengaruh positif dan signifikan antara ketersediaan koleksi buku fiksi terhadap minat kunjung siswa di perpustakaan SMK Muhammadiyah Gamping".

Selanjutnya menghitung besarnya pengaruh koleksi fiksi terhadap minat kunjung siswa dengan mengkuadratkan koefisien korelasi. Dalam menganalisis persentase tersebut, digunakan program SPSS versi 22 for windows. Berikut hasil persentase pengaruh variabel ketersediaan koleksi dan variabel minat kunjung.

Tabel 6. Hasil Perhitungan Regresi Linier Sederhana Model Summary

\begin{tabular}{|c|c|c|c|c|c|c|c|c|c|}
\hline \multirow[b]{2}{*}{ Model } & \multirow[b]{2}{*}{$\mathrm{R}$} & \multirow[b]{2}{*}{$\begin{array}{c}\mathrm{R} \\
\text { Square }\end{array}$} & \multirow{2}{*}{$\begin{array}{c}\text { Adjusted } \\
\text { R } \\
\text { Square }\end{array}$} & \multirow{2}{*}{$\begin{array}{l}\text { Std. Error } \\
\text { of the } \\
\text { Estimate }\end{array}$} & \multicolumn{5}{|c|}{ Change Statistics } \\
\hline & & & & & $\begin{array}{l}\text { R Square } \\
\text { Change }\end{array}$ & $\begin{array}{c}\mathrm{F} \\
\text { Change }\end{array}$ & $\mathrm{df1}$ & $\begin{array}{l}\text { df } \\
2\end{array}$ & $\begin{array}{l}\text { Sig. F } \\
\text { Change }\end{array}$ \\
\hline 1 & .644 & .415 & .406 & 3.417 & .415 & $\begin{array}{l}48.88 \\
9\end{array}$ & 1 & $\begin{array}{l}6 \\
9\end{array}$ & .000 \\
\hline
\end{tabular}

Sumber: Data Primer Diolah Mei 2015

Berdasarkan tabel di atas, dapat dilihat $\mathrm{r}$ square sebesar 0,415 . Jadi koefisian determinan pada variabel $\mathrm{X}$ dan variabel $\mathrm{Y}$ adalah $0,415=$ $41,5 \%$. Hal ini diartikan sebagai minat kunjung siswa dipengaruhi oleh ketersediaan koleksi fiksi sebesar $41,5 \%$ dan sisanya $58,5 \%$ dipengaruhi oleh faktor lain.

\section{E. KESIMPULAN}

Berdasarkan hasil penelitian data dan pembahasan mengenai ketersediaan koleksi fiksi dan minat kunjung siswa maka dapat disimpulkan sebagai berikut:

1. Ketersediaan koleksi fiksi di Perpustakaan SMK Muhammadiyah Gamping dikategorikan tinggi dengan skor 3,15.

2. Minat kunjung di Perpustakaan SMK Muhammadiyah Gamping dikategorikan sangat tinggi dengan skor 3,33.

3. Ada pengaruh yang signfikan antara ketersediaan koleksi fiksi terhadap minat kunjung siswa di SMK Muhammadiyah Gamping. Hal tersebut didasarkan oleh korelasi product moment dengan hasil 0,644. Pada taraf signifikan 5\% dengan $\mathrm{N}$ sebesar 71 didapat $r$ tabel sebesar 0,227. Dengan demikian, nilai koefesien korelasi sebesar 0,644 lebih besar dari $\mathrm{r}$ tabel sebesar 0,227 .

4. Minat kunjung siswa dipengaruhi oleh ketersediaan koleksi fiksi sebesar 41,5\% dan sisanya $58,5 \%$ dipengaruhi oleh faktor lain. Nilai tersebut di dapat dari mengkuadratkan nilai korelasi product moment sebesar 0,644 dan hasilnya sebesar 0,415 .

\section{DAFTAR PUSTAKA}

Arikunto, Suharsimi. 2010. Prosedur Penelitian: Suatu Pendekatan Praktek. Jakarta:Rineka Cipta.

Bafadal, Ibrahim. 2008. Pengelolaan Perpustakaan Sekolah. Jakarta: Bumi Aksara.

Darmono. 2007. Perpustakaan Sekolah: Pendekatan Aspek Manajemen dan Tata Kerja. Jakarta: Grasindo.

Departemen Pendidikan Nasional. 2008. Kamus Besar Bahasa Indonesia. Jakarta: Balai Pustaka.

Gren, boy., Ardoni. 2012. "Pemanfaatan Bahan Pustaka dan Waktu Kunjung Bagi Peserta Didik di Perpustakaan SD Negri 29 Dadok Tunggal Hitam Padang”. Dalam Jurnal Ilmu Informasi Perpustakaan dan Kearsipan Vol. 1, No.1. Padang

Hamidi. 2010. Metode Penelitian dan Teori Komunikasi. Malang: UMM Press

Lasa Hs. 2005. Manajemen Perpustakaan. Yogyakarta. Gama Media 
2009. Kamus Kepustakawanan Indonesia. Yogyakarta: Pustaka Book Publisher.

Minderop, Albertine. 2005. Metode Karakterisasi Telaah Fiksi. Jakarta: Yayasan Obor.

Mustafa EQ, Zainal. 2013. Mengurai Variabel Hingga Instrumentasi. Yogyakarta: Graha Ilmu

Pemerintah Republik Indonesia. 2007. UndangUndang Republik Indonesia Nomor 43 Tahun 2007 Tentang Perpustakaan. Jakarta: Pemerintah Republik Indonesia."

PNRI. 2006. Pedoman Perpustakaan Sekolah: IFLA/UNESCO. Jakarta: Perpustakaan Nasional Republik Indonesia.

Qalyubi, Syihabuddin. Dkk. 2007. Dasar-Dasar Ilmu Perpustakaan dan Informasi. Yogyakarta: Jurusan Ilmu Perpustakaan dan Informasi Fakultas Adab dan Ilmu Budaya UIN Suka Yogyakarta.
Sugiyono. 2013. Metode Penelitian Kuantitatif, Kualitatif dan $R \& D$. Bandung: Alfabeta.

Suharso, Puguh. 2009. Metode Penelitian Kuantitatif Untuk Bisnis: PendekatanFilosofis dan Praktis. Jakarta: Penerbit Indeks.

Surachman, Arif. 2010. Manajemen Perpustakaan Sekolah:Sebuah panduan ringkas.

Sutarno, NS. 2003. Perpustakaan dan Masyarakat. Jakarta: Yayasan Obor Indonesia. . 2006. Manajemen Perpustakaan : Suatu Pendekatan Praktik. Jakarta: Sagung Seto.

Suwarno, Wiji. 2009. Dasar-dasar Ilmu Perpustakaan: Sebuah Pendekatan Praktis. Yogyakarta:Ar-Ruzz Media. 